L. Torta, P. Bella, G. Conigliaro, G. Mirabile, V. A. Laudicina, S. Giambra, G. Venturella, M. L. Gargano

\title{
First report of Pleurotus fuscosquamulosus (Pleurotaceae, Basidiomycota) in Italy naturally occurring on new tropical hosts
}

\begin{abstract}
Torta, L., Bella, P., Conigliaro, G., Mirabile, G., Laudicina, V. A., Giambra, S., Venturella, G., Gargano, M. L.: First report of Pleurotus fuscosquamulosus (Pleurotaceae, Basidiomycota) in Italy naturally occurring on new tropical hosts. — Fl. Medit. 29: 197-206. 2019. — ISSN: 11204052 printed, $2240-4538$ online.

Basidiomata of a mushroom macroscopically recognised as Pleurotus cystidosus sensu latu were collected on the trunks of three tropical ornamental trees such as Broussonetia papyrifera, Yucca elephantipes, and Paulownia tomentosa in the Parco d'Orleans, an urban park in the town of Palermo (Sicily, Italy). All the plants showed cavities and white rot symptoms at the base of the trunks. Macro- and microscopic observations on both collected basidiomata and isolated colonies, as well as molecular analysis, allowed identifying the collected basidiomata as Pleurotus fuscosquamulosus and its anamorph as Antromycopsis fuscosquamulosus. These species belong to the subgenus Coremiopleurotus that includes different species producing synnematoid fructifications. The positive reaction of the colonies to the syringaldazine and the artificial inoculation tests on wood blocks of $B$. papyrifera confirmed its white wood rotting activity. To our knowledge, this is the first report of occurring of P. fuscosquamulosus in Italy on three new tropical plant hosts.
\end{abstract}

Key words: Coremiopleurotus, Antromycopsis fuscosquamulosa, white wood rot, syringaldazine.

\section{Introduction}

The genus Pleurotus (Basidiomycota) includes several genetically well-delimited saprotrophs species (Zervakis \& al. 2014), which play fundamental ecological roles in the agroforest ecosystems, and are widely cultivated for food, biotechnological and pharmaceutical purposes (Venturella \& al. 2016). In the last decades fungi belonging to the genus Pleurotus able to synthesize lingo-cellulolytic enzymes, have been investigated for their potential applications in various industrial processes (Elisashvili \& al. 2006; Sekan \& al. 2019). Nevertheless, many of them are rather aggressive on woodwork and standing trees, degrading lignin and causing white rot (Bari \& al. 2017). Among the ca. 30 species and subspecific taxa of Pleurotus, 14 were reported in Europe as frequent, occasional or, very rare species colonizing living trees, decaying wood and vegetal debris (Venturella \& al. 2015). 
The subgenus Coremiopleurotus Hilber, is characterized by the production of the coremioid anamorphic stage Antromycopsis Pat. \& Trabut. Pleurotus cystidiosus O. K. Miller is the type species of the subgenus, described for the first time by Miller (1969) on red maple (Acer rubrum L.) in Indiana (USA). Its anamorphic state was assigned to Antromycopsis macrocarpa (Ellis \& Everh.) Stalpers, Seifert \& Samson (=Antromycopsis broussonetiae Pat. \& Trab.; Patouillard, 1897; Stalpers \& al., 199; Zervakis, 1998). Other tropical taxa are also ascribed to this subgenus, which are very similar in the morphological features, such as Pleurotus abalonus Y. H. Han, K.M. Chen \& S. Cheng, P. australis Cooke \& Massee, P. cystidiosus var. formosensis Moncalvo, P. fuscosquamulosus Reid \& Eicker, P. purpureoolivaceus Segedin, P. K. Buchanan \& J. P. Wilkie, and P. smithii Guzman. All these species are distributed in restricted geographical areas (Zervakis \& al. 2004). Each species of Pleurotus correspond to a specific Antromycopsis anamorph.

In autumn 2016, in the town of Palermo (Sicily, Southern Italy) some gregarious gilled basidiomata, showing the main typical morphological features of $P$. cystidiosus sensu lato (Miller 1969; Guzman \& al. 1991; Zervakis \& al. 1992), were observed on the trunks of three tropical ornamental trees.

\section{Materials and methods}

\section{Sampling of basidiomata}

In autumn 2016, during a survey conducted in Parco d'Orleans some gregarious gilled basidiomata (5 - $15 \mathrm{~cm}$ wide) were observed on forty years old ornamental trees of Broussonetia papyrifera (L.) Vent. (paper mulberry tree), Yucca elephantipes Regel ex Trel. and, Paulownia tomentosa Steud. The basidiomata emerged from cavities localized at the base and along the trunks where white rot symptoms were also observed. No evident symptoms were observed on the aerial parts of the host plants. Samples of basidiomata from each tree species were collected and subjected to laboratory analysis according to Zervakis \& al. (1992, 2004).

\section{Morphological features}

The macroscopic features of basidiomata were detected by naked eye and under a Leica stereoscope microscope. Handmade sections of gills (ca. $20 \mu \mathrm{m}$ thin) and portions of the mycelial culture were mounted in lactophenole clear (phenol 20 g, glycerol $40 \mathrm{ml}$, lactic acid $20 \mathrm{ml}$, deionized water $20 \mathrm{ml})$ or with methyl blue $(0.05 \%)$ and the slides observed at light microscope (Axioskop; Zeiss, Oberkochen, Germany) coupled to an AxioCam MRc5 (Zeiss, Oberkochen, Germany) digital camera. Images were captured using the software AxioVision 4.6 (Zeiss, Oberkochen, Germany). The collected data were shape, color and structure of the basidiomata; morphology of basidia, basidiospores and anamorphic structures; macroscopic and, microscopic colony characteristics. The size of the microscopic structures was calculated based on the arithmetic mean of the values of 50 measurements.

\section{Fungal culture}

In order to obtain the dikaryotic fungal colonies, three young basidiomata grown on each host were collected and transferred to the laboratory for isolation. In particular, after 
a fast passage over the flame, each basidioma was aseptically dissected and 20 little fragments (ca. $2 \mathrm{~mm}$ in size) of the inner pseudo-parenchyma were removed and plated on Potato Dextrose Agar (PDA, Oxoid), in Petri dishes (5 fragments for dish). The Petri dishes were incubated at $25^{\circ} \mathrm{C}$, until the grown of the fungal colonies. Mono-hyphal pure cultures were obtained by transferring on PDA hyphal tips by means of a thin sterile needle under stereomicroscope.

\section{Molecular and phylogenetic analysis}

Genomic DNA was isolated from 1-week-old fugal isolate grown on PDA at $25^{\circ} \mathrm{C}$ in the dark using a standard CTAB based-protocol (Torta \& al., 2015). The internal transcribed space (ITS) regions, ITS1 and ITS2, and the 5.8S gene of the ribosomal DNA (rDNA) operon, were amplified using primers ITS1F (fungal specific: 5'- CTTGGTCATTTAGAGGAAGTAA-3') (Gardes \& Bruns, 1993) and ITS4 (universal: 5'-TCCTCCGCTTATTGATATGC-3') (White \& al., 1990). The amplification reaction was performed in a total reaction volume of $25 \mu \mathrm{l}$ containing $50-100 \mathrm{ng}$ of DNA template, $2 \mathrm{mM}$ of $\mathrm{MgCl}_{2}, 0.2$ $\mathrm{mM}$ of each dNTP, $0.2 \mu \mathrm{M}$ of each primer, $0.2 \mathrm{U}$ of Dream Taq (Fermentas, Milan, Italy) and $1 \times$ Dream Taq buffer (Fermentas). The amplification reaction was carried out as follows: initial denaturation at $95^{\circ} \mathrm{C}$ for $2 \mathrm{~min}, 35$ cycles of denaturation at $95^{\circ} \mathrm{C}$ for $30 \mathrm{~s}$, annealing at $55^{\circ} \mathrm{C}$ for $20 \mathrm{~s}$, extension at $72{ }^{\circ} \mathrm{C}$ for $1 \mathrm{~min}$ and final extension at $72^{\circ} \mathrm{C}$ for $5 \mathrm{~min}$.

Results PCR products were analyzed by electrophoresis on $1,5 \%$ agarose gel, stained with SYBR Safe DNA gel stain and visualized under a UV transilluminator.

PCR products were sequenced in both directions using the same primers as for PCR reactions. Sequences were edited using the Sequencer software (Version 4.7, Gene Codes Corporation, Ann Arbor, MI) and compared to GenBank sequences through BLASTn searches. ITS sequence was aligned using MEGA6 software (Tamura \& al., 2011) and manual adjustments of alignments were made when necessary. Phylogenetic analysis was performed according to Giambra \& al. (2016) by using sequences of 26 Pleurotus species belonging to subgenus Coremiopleurotus retrieved from GenBank. P. australis (Accession number AY450342) was used as outgroup.

\section{Enzymatic activity}

The production of laccase by the fungal colonies was detected by the use of syringaldazine, an organic azo-compound oxidizable by this enzyme, turning from light yellow to dark red colour (Wilkołazka \& al. 2002; Floch \& al. 2007; Wang \& al. 2010). Drops of a mixture containing $0.2 \mathrm{mM}$ syringaldazine (dissolved in $60 \%$ ethanol) in $40 \mathrm{mM}$ citratebuffer ( $\mathrm{pH}$ 5.6) were applied on the surface of the fungal colony. As negative control, colonies of Fusarium oxysporum von Schlechtendal no producing laccase were employed.

\section{Inoculation on sapwood block}

To confirm the ligninolytic activity, blocks of healthy wood of B. papyrifera $(10 \times 5 \times 5 \mathrm{~cm})$ were singularly put into 10 moist chambers (autoclavable plastic airtight containers of $200 \mathrm{ml}$ volume, with adsorbing paper), added with $5 \mathrm{ml}$ of distilled sterile water and sterilized in autolclave. Plugs $\left(5 \mathrm{~mm}^{2}\right)$ of 10 days old colonies grown on PDA were inoculated singularly on 7 wood samples, and the remaining 3 samples were inoculated with plugs of sterile PDA. All the containers were incubated at $25^{\circ} \mathrm{C}$ in the dark for six months (Burcham \& al. 2015). 


\section{Results}

The young basidiomata (5-7 cm broad) caps varied from gray to light brown - pale yellow and were sub-globose or plane-convex, enrolled, with cuticle brown squamulose. The ripe basidomata $(10-15 \mathrm{~cm})$ were more or less depressed in the center, with involute margins. Both in young and ripe basidiomata the lamellae were thin, wide, and decurrent with some anastomoses at the top of the stipe, alternate by long lamellulae. In the older samples colour of the lamellae varied from cream white, to pale yellow or light orange ocher. Stipes, typically eccentric, in the ripe basidiomata, were fibrous, thick, fistulose, with a tapered base and light brown in colour (Fig. $1 \mathrm{a}-\mathrm{c}$ ). Basidia and spores were hyaline and smooth walled, the first measuring $40 \times 7 \mu \mathrm{m}$, and the latter, oblong, about $15 \times 5 \mu \mathrm{m}$ (Fig.1 d-e). The basidiospores, in mass, were whitish. All the macroscopic features permitted to identify the collected fungi as P. cystidiosus s. 1 .

On PDA fungal colonies were white, with radial growth and irregular margins, covering the plates in 50 days and constituted by hyaline and clamped mycelium (Fig. 2 a-b). From young colonies, whitish and cespitose coremia were produced, bringing globose black heads made up by mass of dark, cylindrical conidia originate from disarticulation of the ending hyphae, measuring $15.5 \times 6 \mu \mathrm{m}$. All typical structures of the anamorph belonging to the genus Antromycopsis (Fig. 2 c-d).

Since morphological characters alone were ineffective for identifying the species within the $P$. cystidiosus s. 1., a phylogenetic analysis based on ITS sequences was performed. ITS sequence of the isolate obtained in this study deposited in GenBank with the accession number MH271184 was compared with sequences of 26 isolated of the species within subgenus Coremiopleurotus retrieved from GenBank database. The phylogenetic tree constructed by the Maximum Likelihood method showed that the isolate obtained in this study grouped with other P. fuscosquamulosus isolates with high bootstrap value and was differentiated from other clusters including other Pleutotus species (Fig. 3).

In our study, laccase production was assayed by a colorimetric qualitative test based on syringaldazine oxidation. The quick turning from light yellow to dark red of few drops of the solution containing the syringaldazine applied on the surface of fungal colony indicated the production of the ligninolytic enzyme by the fungal isolate. (Fig. 4a). No activity was observed in the colony of the negative control (Fig. 4b). Moreover, in the inoculated wood blocks of $B$. papyrifera coarse mass of white mycelium associated with the above described coremia was observed. All the infected blocks showed symptoms of white rot (Fig. 4c), confirming the degradation activity on the lignin compounds.

\section{Discussions and Conclusion}

A basidiomycete belonging to the subgenus Coremiopleurotus, growing on ornamental tropical trees in a urban Park of Palermo, was identified at species level. To our knowledge, this is the first report of $P$. fuscosquamulosus in Italy. The last report of Coremiopleurotus in Greece (Zervakis \& al. 1992) and the presence of new fructifications of P. cystidiosus s. 1. on different trees of $B$. papyrifera observed in the same location in summer 2019, seems indicate the spreading of the subgenus also in the Mediterranean area. 


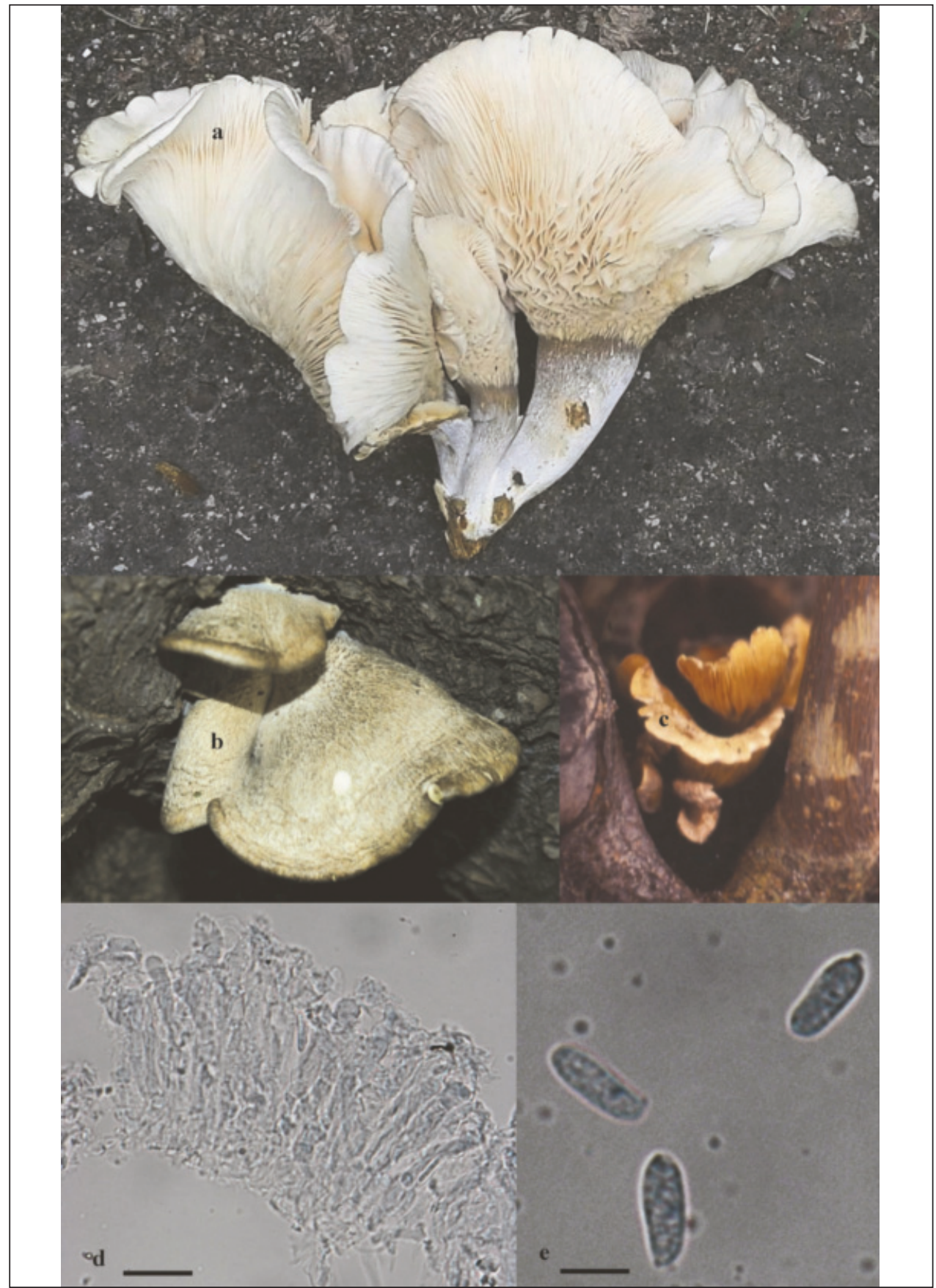

Fig. 1. Main morfological features of the collected basidioma. Fruiting bodies grown on P. tomentosa (a), Y. elephantipes (b) and B. papyrifera (c); microscopic features of basidia (d) and basidiospores (e). Bars: $\mathrm{d}=20 \mu \mathrm{m}$; e $=10 \mu \mathrm{m}$. 


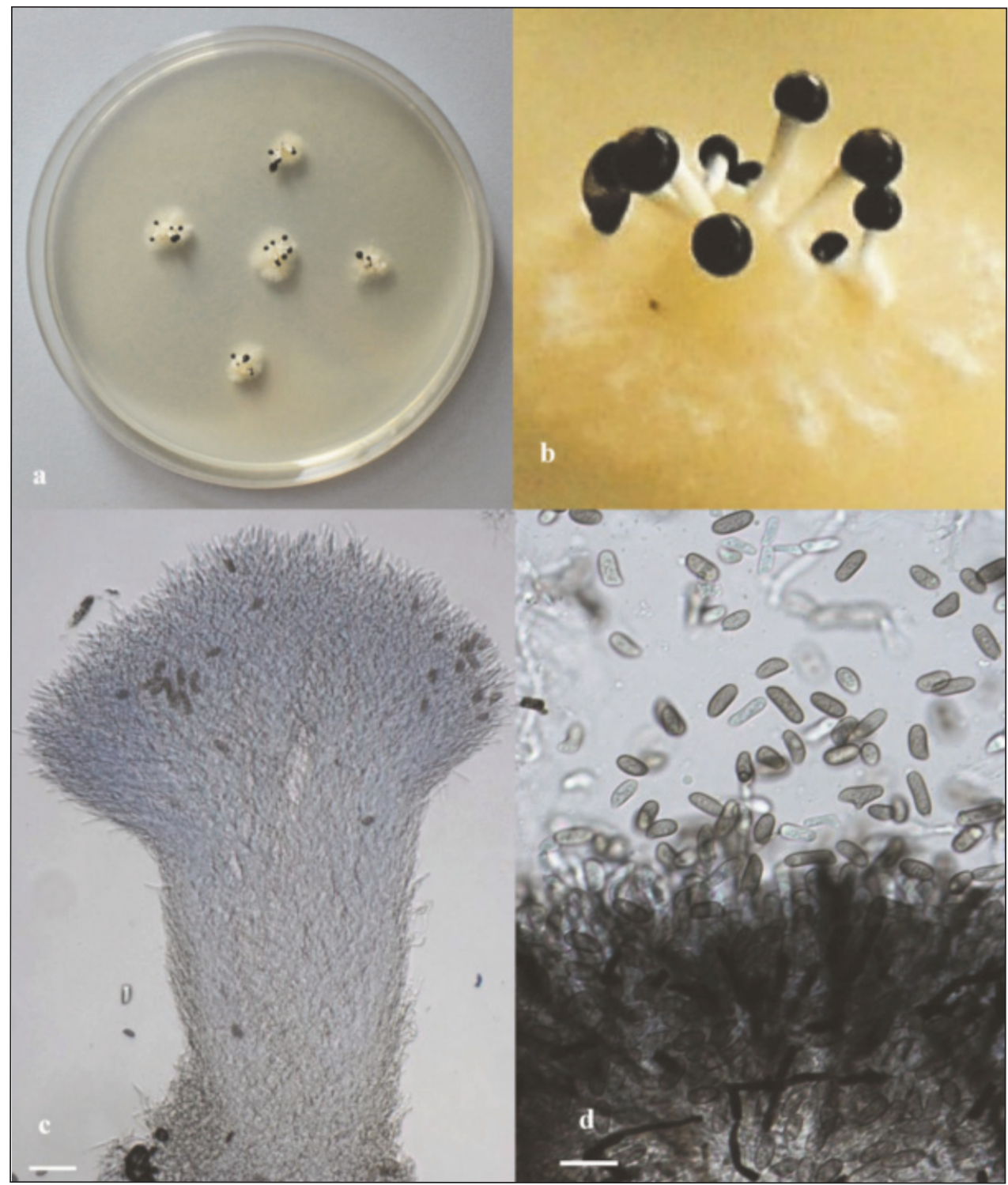

Fig. 2. Young colonies of Pleurotus fuscosquamulosus and coremia of Antromicopsis fuscosquamulosus on PDA $(\mathrm{a}, \mathrm{b})$ and at microscope $(\mathrm{c}, \mathrm{bar}=10 \mu \mathrm{m} ; \mathrm{d}$, bar $=20 \mu \mathrm{m})$.

P. fuscosquamulosus and the anamorphic stage Antromycopsis fuscosquamulosus D. A. Reid \& Eicker were described for the first time by Reid and Eicker (1998) on trunk and roots of Populus alba L. and Combretum molle R. Br. ex G. Don in South Africa. More recently, Zervakis \& al. (2004), reported the only presence of P. fuscosquamulosus also in Europe (Greece), distinguishing this species from other belonging to the 


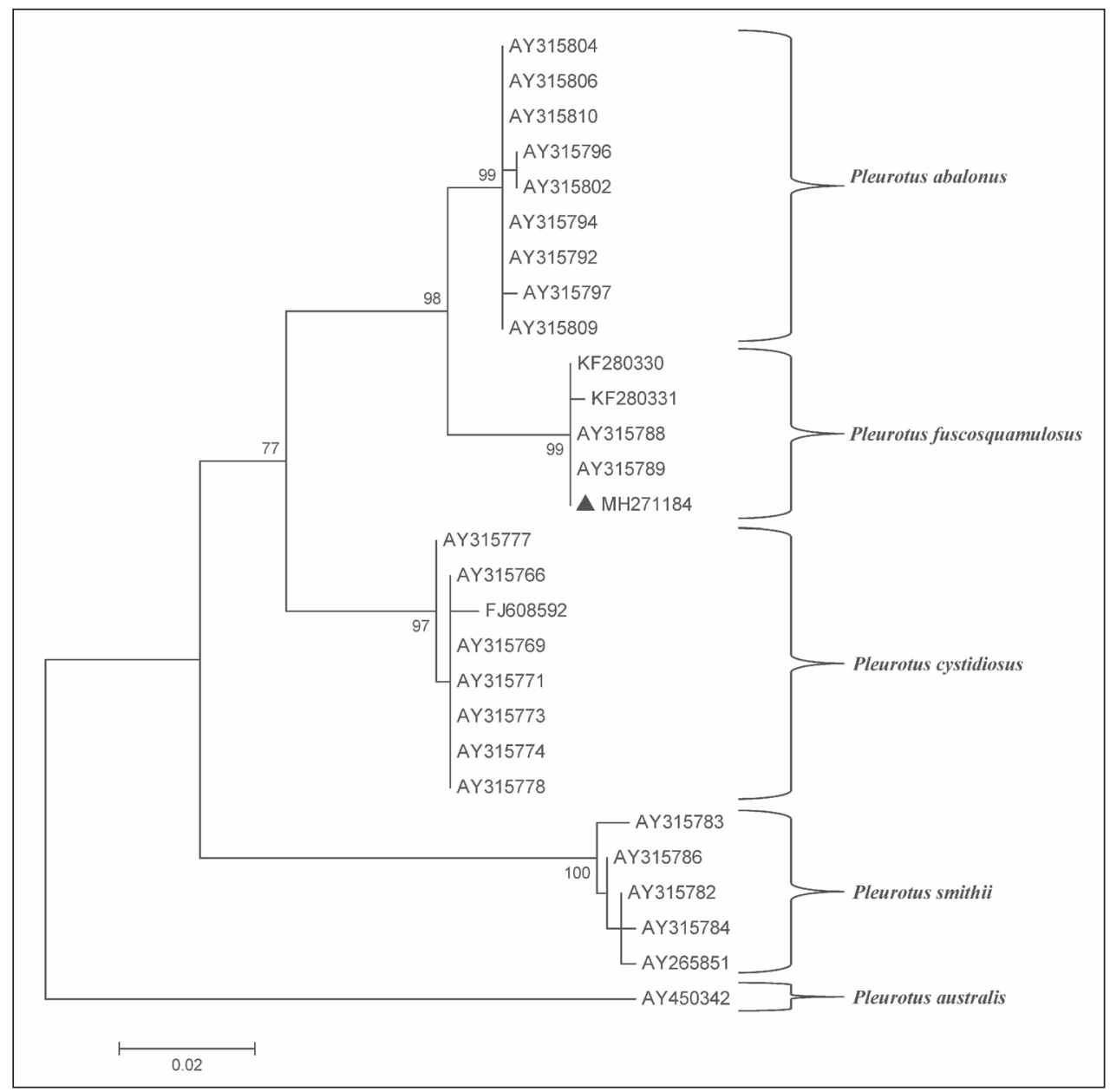

Fig. 3. Maximum likelihood trees based on ITS sequences of 26 isolates of Pleurotus sp. within the subgenus Coremiopleurotus. P. australis was used as outgroup. Black triangle indicates the isolate obtained during this study, whereas the other ITS sequences were retrieved from GenBank and are shown with their Accession Number. Bootstrap tests were performed with 1,000 replications.

Coremiopleurotus, based on phylogenetic species concept, molecular, mating and geographical evidence (Denchev \& al. 2013). In the last few years, Menolli \& al. (2014) reported the presence of the species in Brazil. Very few information is available on the host plant from which this Coremiopleurotus species was found. In this survey, P. fuscosquamulosus was reported on new tropical hosts $B$. papyrifera, Y. elephantipes and P. tomentosa. as potential white rot etiological agent.

The close resemblance between the members of the Pleurotus subgenus Coremiopleurotus, mainly in the macroscopic features, can lead to misidentification, if based only on the traditional taxonomy. 


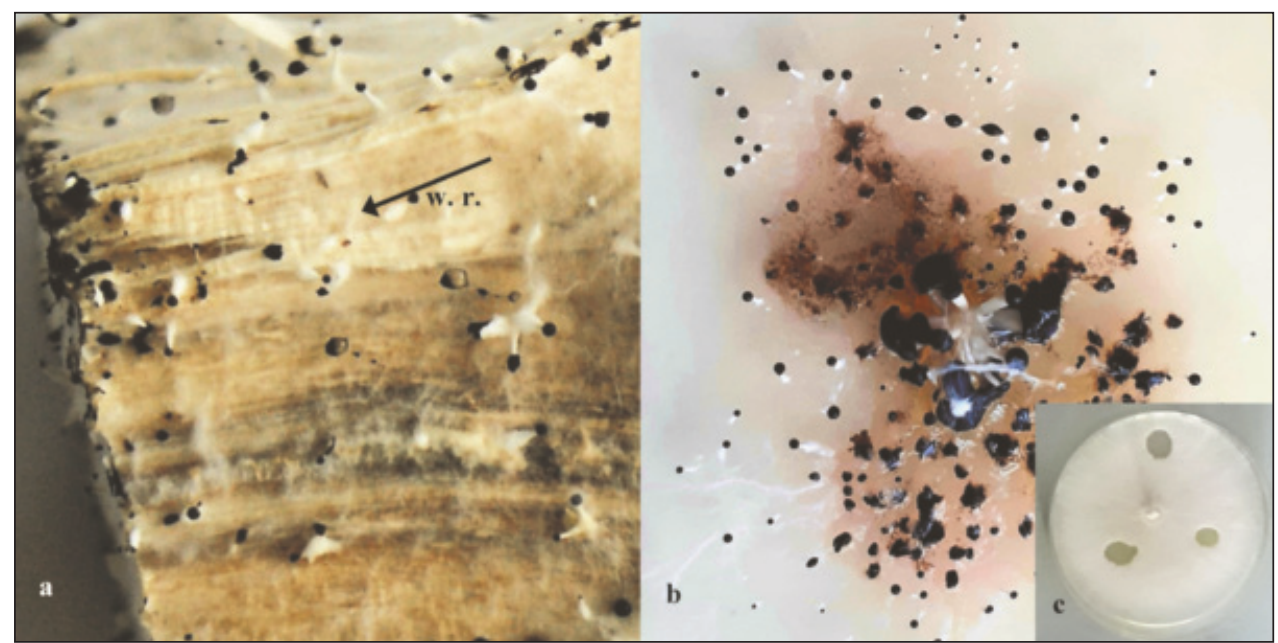

Fig. 4. Mycelial growth of $P$. fuscosquamulosus artificially inoculated on wood samples of $B$. papyrifera and symptoms of white rot (w. r.) (a). Reaction to syringaldazine in colonies of $P$. fuscosquamulosus (b) and of a not producing laccase fungus (c)

Like most Pleurotus species, the fungi belonging to the Coremiopleurotus produce good edible basidiomata. For food purposes and for the high commercial value P. cystidiosus and related species are widely cultivated in the United States, Canada, Europe, Asia, and, Australia (Zervakis \& al. 2004). This species showed also antihypertensive hypotheses (Ching \& al. 2011, 2013) and hypoglycaemic activities (Jayasuriya \& al. 2015). However, data on the cultivation and medical properties of $P$. fuscosquamulosus are not known. Investigations on edible fungi producing lignin-cellulosolytic enzymes and other active secondary metabolites can be useful to the development of new strategies in food, pharmaceutical and industrial fields.

\section{References}

Bari, E., Karim, M., Oladi, R., Tajick Ghanbary, M. A., Ghodskhah Daryaei, M., Schmidt, O., Benz, J. P. \& Emaminasab, M. 2017: A comparison between decay patterns of the white-rot fungus Pleurotus ostreatus in chestnut-leaved oak (Quercus castaneifolia) shows predominantly simultaneous attack both in vivo and in vitro. - Forest Pathol. 47: e12338. https://doi.org/10.1111/efp.12338

Burcham, D. C., Wong, J. Y., Ali, M. I. M., Abarrientos, N. V. Jr, Fong, Y. K. \& Schwarze, F. W. M. R. 2015: Characterization of host-fungus interactions among wood decay fungi associated with Khaya senegalensis (Desr.) A. Juss (Meliaceae) in Singapore. - Forest Pathol. 45(6): 492504. https://doi.org/10.1111/efp.12199

Ching, L. C., Abdullah, N. \& Shuib, A. S. 2013. Novel angiotensin I-converting enzyme inhibitory peptides derived from an edible mushroom, Pleurotus cystidiosus O.K. Miller identified by LC-MS/MS. - Complem. Altern. Med. 13: 313. https://doi.org/10.1186/1472-6882-13-313 
—, 一, — \& Aminudin, N. 2011. Characterization of antihypertensive peptides from Pleurotus cystidiosus O.K. Miller (abalone mushroom). - Pp. 319-328 in: Proceedings of the $7^{\text {th }}$ International Conference on Mushroom Biology and Mushrooms Products. - Arcachon.

Denchev, C. M., Venturella, G. \& Zervakis, G. (eds) 2013. MYCOTICON (MYCOTa Intereuropean COoperation Network) "Identification and sustainable exploitation of wild edible mushrooms in rural areas". - Larissa.

Elisashvili, V., Penninckx, M., Kachlishvili, E, Asatiani, M. \& Kvesitadze, G. 2006: Use of Pleurotus dryinus for lignocellulolytic enzymes production in submerged fermentation of mandarin peels and tree leaves. - Enzyme Microb. Technol. 38: 998-1004. https://doi.org/10.1016/j.enzmictec.2005.08.033

Floch, C., Alarcon-Gutierrez, E. \& Criquet, S. 2007: ABTS assay of phenol oxidase activity in soil. - J. Microbiol. Meth. 71: 319-324. https://doi.org/10.1016/j.mimet.2007.09.020

Gardes, M. \& Bruns, T. D. 1993: ITS primers with enhanced specificity for basidiomycetes - application to the identification of mycorrhizae and rusts. - Molec. Ecol. 2(2): 113-118. https://doi.org/10.1111/j.1365-294x.1993.tb00005.x

Giambra, S., Piazza, G., Alves, A., Mondello, V., Berbegal, M., Armengol, J. \& Burruano, S. 2016: Botryosphaeriaceae species associated with diseased loquat trees in Italy and description of Diplodia rosacearum sp. nov. - Mycosphere 7(special issue): 978-989. https://doi.org/10.5943/mycosphere/si/1b/9

Guzmán, G., Bandala, V. M. \& Montoya, L. 1991: A comparative study of teleomorphs and anamorphs of Pleurotus cystidiosus and Pleurotus smithii. - Mycol. Res. 95(11): 1264-1269. https://doi.org/10.1016/s0953-7562(09)80572-8

Jayasuriya, W. J., Wanigatunge, C. A., Fernando, G. H., Abeytunga, D. T. \& Suresh, T. S. 2015. Hypoglycaemic activity of culinary Pleurotus ostreatus and P. cystidiosus mushrooms in healthy volunteers and type 2 diabetic patients on diet control and the possible mechanisms of action. - Phytother. Res. 29: 303-309. https://doi.org/10.1002/ptr.5255

Miller, O. K. 1969. A new species of Pleurotus with a coremioid imperfect stage. - Mycologia, 61: 887-893. https://doi.org/10.1080/00275514.1969.12018812

Menolli, N., Breternitz B. S. \& Capelari, M. 2014: The genus Pleurotus in Brazil: a molecular and taxonomic overview. - Mycoscience 55(5): 378-389. https://doi.org/ 10.1016/j.myc.2013.12.001

Patouillard, N. 1897. Additions au catalogue des champignons de la Tunisie. - Bull. Soc. Fr. Mycol. 13: $197-216$.

Reid, D. A., Eicker, A. \& de Kock, A. 1998: Pleurotus fuscosquamulosus a new species of Pleurotus subgenus Coremiopleurotus from South Africa. - Mycotaxon. 66: 137-152.

Sekan, A. S., Myronycheva, O. S., Karlsson, O., Gryganskyi, A. P. \& Bluma, Y. 2019: Green potential of Pleurotus spp. in biotechnology. - Peer J. 7: e6664 https://doi.org/10.7717/peerj.6664

Stalpers, J. A., Seifert, K. A. \& Samson, R. A. 1991: A revision of the genera Antromycopsis, Sclerostilbum and Tilachlidiopsis (Hyphomycetes). - Canad. J. Bot. 69(1): 6-15. https://doi.org/10.1139/b91-002

Tamura, K., Peterson, D., Peterson, N., Stecher, G., Nei, M. \& Kumar, S. 2011: MEGA5: molecular evolutionary genetics analysis using maximum likelihood, evolutionary distance, and maximum parsimony methods. - Mol. Biol. Evol. 28(10): 2731-2739. https://doi.org/10.1093/molbev/msr121

Torta, L., Lo Piccolo, S., Piazza, G., Burruano, S., Colombo, P., Ottonello, D., Perrone, R., Di Maida, G., Pirrotta, M., Tomasello, A. \& Calvo, S. 2015: Lulwoana sp., a dark septate endophyte in roots of Posidonia oceanica (L.) Delile seagrass. - Pl. Biol. 17(2): 505-511. https://doi.org/10.1111/plb.12246

Venturella, G., Gragano, M. L. \& Compagno, R. 2015. The genus Pleurotus in Italy. - Fl. Medit. 25: 143-155. 
—, Zervakis, G., Polemis, E. \& Gargano, M. L. 2016: Taxonomic Identity, Geographic Distribution, and Commercial Exploitation of the Culinary-Medicinal Mushroom Pleurotus nebrodensis (Basidiomycetes). - Int. J. Med. Mushrooms 18(1): 59-65. https://doi.org/10.1615/intjmedmushrooms.v18.i1.70

Wang, C., Zhao, M., Li, D., Cui, D., Lu, L. \& Wei, X. D. 2010. Isolation and characterization of a novel Bacillus subtilis WD23 exhibiting laccase activity from forest soil. - Afr. J. Biotech. 9: 5496-5502. https://doi.org/10.4028/www.scientific.net/amr.113-116.725

White, T. J., Bruns, T. D., Lee, S. B \& Taylor, J. W. 1990. Amplification and direct sequencing of fungal ribosomal RNA Genes for phylogenetics. - Pp. 315-322 in: PCR - Protocols and Applications - A Laboratory Manual. - Cambridge. https://doi.org/10.1016/b978-0-12372180-8.50042-1

Jarosz-Wilkołazka, A., Kochmańska-Rdest, J., Malarcżyk, E., Wardas, W. \& Leonowicz, A. 2002: Fungi and their ability to decolorize azo and antraquinonic dyes. - Enzyme Microb. Technol. 30: 566-572. https://doi.org/10.1016/s0141-0229(02)00022-4

Zervakis, G. 1998: Mating competence and biological species within the subgenus Coremiopleurotus. - Mycologia 90: 1063-1074. https://doi.org/ 10.1080/00275514.1998.12027006

—, G., Dimou, D. \& Balis, C. 1992: First record of the natural occurrence in Europe of the basidiomycete Pleurotus cystidiosus on a new host. - Mycol. Res. 96: 874-876. https://doi.org/ 10.1016/s0953-7562(09)81034-4

—, Moncalvo, J. M. \& Vilgalys, R. 2004. Molecular phylogeny, biogeography and speciation of the mushroom species Pleurotus cystidiosus and allied taxa. - Microbiology 150: 715-26. https://doi.org/10.1099/mic.0.26673-0

—, Ntougias, S., Gargano, M. L, Besi, M. I, Polemis, E., Typas, M. A \& Venturella, G. 2014. A reappraisal of the Pleurotus eryngii complex - New species and taxonomic combinations based on the application of a polyphasic approach, and an identification key to Pleurotus taxa associated with Apiaceae plants. - Fungal Biol. 118(9): 814-834. https://doi.org/ 10.1016/j.funbio.2014.07.001

Address of the authors:

Livio Torta*, Patrizia Bella, Gaetano Conigliaro, Giulia Mirabile, Vito Armando Laudicina, Selene Giambra, Giuseppe Venturella \& Maria Letizia Gargano,

Department of Agricultural, Food and Forest Sciences, University of Palermo, Viale delle Scienze, 90128, Palermo, Italy. E-mail: livio.torta@unipa.it

*Corresponding author 